\title{
A survey of adult referrals to specialist attention- deficit/hyperactivity disorder clinics in Canada
}

This article was published in the following Dove Press journal: International Journal of General Medicine

\section{Larry J Klassen' \\ C Matthew Blackwood ${ }^{2}$ Christopher J Reaume ${ }^{3}$ \\ Samuel Schaffer ${ }^{3}$ \\ James G Burns ${ }^{3}$}

'Eden Mental Health Centre, Winkler, $\mathrm{MB},{ }^{2}$ Cedar Care Clinic, Mission, BC, ${ }^{3}$ International Medical Affairs, Shire Pharma Canada ULC, Toronto, ON, Canada

Correspondence: James G Burns International Medical Affairs, Shire Pharma Canada ULC, Bay Adelaide Centre, 22 Adelaide Street West, Suite 3800 , Toronto, ON M5H 4E3, Canada $\mathrm{Tel}+\mathrm{I} 6043635185$ Email jaburns@shire.com
Background: Canadian guidelines encourage family physicians to diagnose/manage adults with uncomplicated attention-deficit/hyperactivity disorder (ADHD); specialist referral is recommended only for complex cases. This retrospective case review investigated adults referred to Canadian ADHD clinics.

Methods: Adult ADHD specialists reviewed referral letters/charts of patients (aged $\geq 18$ years and no family history/known/expressed childhood ADHD) from family physicians/psychiatrists over 2 years.

Results: Data on 515 referrals (mean age 33 years, 60\% males) were collected (December 2014 to September 2015); 472/515 (92\%) were made by family physicians. No psychiatric comorbid symptoms were noted in 344/515 (67\%) referrals. ADHD was confirmed by a specialist in 483/515 (94\%) cases, whether comorbid symptoms were noted at referral (155/171 [91\%]) or not (328/344 [95\%]). ADHD was reported to impact "work" (251/317 [79\%]), "school" (121/166 [73\%]), "social/friends" (260/483 [54\%]), and "spouse/family" (231/483 [48\%]). Overall, 335/483 (69\%) patients had more than or equal to one comorbid symptom (diagnosed by referring physician or specialist). Stimulant monotherapy was recommended for 383/483 (79\%) patients, non-stimulant monotherapy for $41 / 483$ (8\%) patients, and stimulant plus nonstimulant monotherapy for 39/483 (8\%) patients. Almost half of patients were returned for referring physician's follow-up, either before treatment initiation (102/483 [21\%]) or after treatment stabilization (99/483 [20\%]). Follow-up was by a specialist for 282/483 (58\%) patients. Conclusion: ADHD diagnosis was specialist confirmed in most cases. Although most referrals $(67 \%)$ noted no psychiatric comorbid symptoms, $69 \%$ of patients had $\geq 1$ such symptom (diagnosed by a referring physician or specialist), so comorbid symptoms although not always noted at referral, may have contributed to the decision to refer. ADHD has a wide-ranging impact on patients' daily lives. It is possible that greater confidence of family physicians to diagnose and treat adult ADHD could help to meet patients' needs.

Keywords: attention-deficit/hyperactivity disorder, adult, Canada, diagnosis, comorbid symptoms, family medicine/general practice/primary care

\section{Introduction}

Attention-deficit/hyperactivity disorder (ADHD) is a disabling neurobehavioral disorder characterized by core symptoms of inattentiveness, hyperactivity, and impulsivity. Although traditionally perceived as a disease of childhood and adolescence, ADHD has a prevalence of up to $5 \%$ in adults ${ }^{1}$ in whom it causes functional impairment and adversely affects health-related quality of life. ${ }^{2}$ Adults with ADHD are more likely than their non-ADHD counterparts to experience difficulties with academic studies, 
employment, and emotional relationships and to commit a criminal offense or display antisocial behavior. ${ }^{3}$ Comorbid psychiatric disorders occurring with ADHD are commonplace in adults with $\mathrm{ADHD},{ }^{4-6}$ and comorbid impulsive disorders and substance use may further complicate patient management. ${ }^{7}$

Diagnosis/treatment of adult ADHD tends to be offered by only a limited number of specialist centers. ${ }^{8}$ The use of specialist care alone is not a viable health care model, and Canadian guidelines encourage family physicians to diagnose/manage adults with uncomplicated ADHD within primary care. ${ }^{9}$ Specialist referral is recommended only for complex cases, such as when there are comorbid conditions, if another diagnosis could be possible (i.e., disorders that mimic ADHD), or there is a need for management with multiple interventions or medications. ${ }^{9}$ In such cases, once the patient is assessed and treatment initiated, follow-up can be undertaken by the family physician. ${ }^{9}$ In reality, many family physicians are reluctant to diagnose and treat even uncomplicated adult ADHD, likely due to various reasons including the need to rely on subjective reports of symptoms, subtle differences in symptoms of ADHD in adults compared to those in children/adolescents, and a perceived need to adopt a cautious approach in prescribing stimulant treatment. ${ }^{10}$ Inadequate training in ADHD and comorbidities may also contribute to this reluctance. The objective of this survey was to evaluate whether family physicians diagnosed and treated uncomplicated ADHD (as per the recommendation) through investigation of the referral of adult patients by family physicians to ADHD specialist clinics, as well as to examine the impact of adult ADHD on daily life. This was explored by conducting a case review of the clinical presentation, disease burden, and treatment of adults referred to adult ADHD specialist clinics in Canada. Specifically, the survey assessed information regarding comorbid symptoms, impact of ADHD on life function, types of medication prescribed, and delay from referral to treatment.

\section{Methods}

\section{Study design and setting}

This was an open-label, noninterventional, retrospective survey of referrals of adults with suspected ADHD from family physicians or nonspecialist psychiatrists to a specialist in adult ADHD. Data were collected between December 2014 and September 2015 from original referral letters and ADHD specialists' charts and used to complete a case report form (CRF) for each patient. Data were anonymized; patients were not identifiable and could not be linked back to a specific site. The survey was reviewed and approved by the Canadian SHIELD Ethics Review Board. As data were de-identified and complied with the patient confidentiality requirements of the ethics review board, patient consent was not obtained for this study.

\section{Study population}

Canadian adult ADHD medical specialists (physicians specializing in adult ADHD and practicing at clinics in Canada and who were recognized by their local communities as ADHD specialists) were identified and contacted via fax and/or email to request their participation; 19 specialists participated in the study.

\section{Inclusion criteria}

Referrals of adults ( $\geq 18$ years of age at the time of ADHD diagnosis) to adult ADHD specialists made in the previous 2 years were included if ADHD was suspected by the family physician (as indicated in the referral note).

\section{Exclusion criteria}

Patients were excluded if they had an expressed or known prior family history of ADHD or an expressed or known childhood history of ADHD.

\section{Survey instrument}

A CRF was completed for each patient detailing the information listed in Table S1, including patient demographics (age, sex, employment status) and the measurements described below (see Measurements section).

\section{Accuracy of the survey instrument}

Data entry from each CRF was performed by an independent data entry specialist from Drug Intelligence Inc. (Toronto, Canada), and double data entry verification was used to ensure the accuracy of data entry.

\section{Measurements}

\section{Reasons for referral to adult ADHD specialist}

Reasons for referral included the referring physician mentions ADHD or symptoms implying ADHD, with no comorbid symptoms noted; the referring physician mentions ADHD with other comorbid symptoms; the patient/family suspects ADHD with no comorbid symptoms noted; the patient/family suspects ADHD and the patient has comorbid symptoms; or the patient mentions symptoms not limited to ADHD.

\section{Delay from referral request to actual patient consultation by ADHD specialist}

This delay was the time in months between referral and initial consultation with an ADHD specialist. 


\section{Prevalence of ADHD symptoms}

Data were combined from the "reason/trigger for consultation request as per referral note", "complaints verbalized by patient to ADHD specialist at initial assessment", and "ADHD symptoms as interpreted by ADHD specialists" sections of the CRFs. Two observers (JGB and SS) independently reviewed the data to list the symptoms for each patient according to predefined categories (Table S2).

\section{Prevalence of comorbid symptoms}

Comorbidities were reported in CRFs but not always stated as a specific, confirmed Diagnostic and Statistical Manual of Mental Disorders, Fifth Edition (DSM-5) diagnosis ${ }^{11}$ and thus were interpreted only as "comorbid symptoms". Comorbid symptoms included (with examples of wording) depression (e.g., major depressive disorder, depression), anxiety (e.g., social anxiety disorder, generalized anxiety disorder, anxiety), other mood disorders (e.g., bipolar disorder, dysthymia), substance abuse (e.g., opioid addiction, alcohol abuse disorder, substance abuse), and other (e.g., Tourette's, obsessive-compulsive disorder, borderline personality disorder).

\section{Impact of ADHD on patients' daily life}

The impact of ADHD on school/work, relationships with spouse/family, social life and friends, money management, and other areas was reported by the specialist and categorized.

\section{Employment status}

Four patient profiles with respect to status of employment were described post hoc: college/university student, employed young adult (18-25 years old), employed adult ( $>25$ years old), and unemployed adult ( $>25$ years old).

\section{Follow-up care after ADHD diagnosis}

The use of pharmacologic ADHD treatments prescribed by the specialist (stimulant monotherapy, non-stimulant monotherapy, stimulant plus non-stimulant) after diagnosis (also by the specialist) was recorded. Continuing care was described as follows: patients returned to the care of the referring physician, patients stabilized on treatment and then returned to the care of their referring physician, or follow-up retained by the specialist. The data comparing those patients who were retained by the ADHD specialist versus those who were sent back to the referring physician (with or without initiation of treatment) were explored further to investigate whether any patient characteristics such as sex, age, or comorbid symptoms affected the course of continuing care.

\section{Statistics}

Data from this survey were descriptive. No inferential statistical analyses were performed.

\section{Results}

\section{Participants}

A total of 515 referrals fitting the inclusion criteria were collected (one referral did not meet inclusion criteria). Of the 19 specialists, 10 were interviewed over phone by Drug Intelligence Inc. to complete the CRFs; nine specialists completed the CRFs directly. The demographic characteristics of the referrals, both for the overall sample and by ADHD status, are summarized in Table 1 . Of the 515 cases, 483 (93.8\%) had an ADHD diagnosis made by the adult ADHD

Table I Patients' demographic characteristics for the overall sample and by ADHD status

\begin{tabular}{|c|c|c|c|}
\hline Characteristic, n (\%) & Overall $(\mathrm{N}=5 \mid 5)$ & $\begin{array}{l}\text { ADHD confirmed } \\
(n=483)\end{array}$ & $\begin{array}{l}\text { ADHD not confirmed } \\
(n=32)\end{array}$ \\
\hline \multicolumn{4}{|l|}{ Sex } \\
\hline Male & $310(60.2)$ & $287(59.4)$ & $23(71.9)$ \\
\hline Female & $205(39.8)$ & $196(40.6)$ & $9(28.1)$ \\
\hline \multicolumn{4}{|l|}{ Age, years } \\
\hline $18-25$ & $176(34.2)$ & $165(34.2)$ & II (34.4) \\
\hline $26-45$ & $252(48.9)$ & $236(48.9)$ & $16(50.0)$ \\
\hline $46-65$ & $83(16.1)$ & $79(16.4)$ & $4(12.5)$ \\
\hline$>65$ & $4(0.8)$ & $3(0.6)$ & $I(3.1)$ \\
\hline \multicolumn{4}{|l|}{ Employment status } \\
\hline College student & $173(33.6)$ & $166(34.4)$ & 7 (21.9) \\
\hline Employed, young adult & $52(10.1)$ & $48(9.9)$ & $4(12.5)$ \\
\hline Employed, adult & $197(38.3)$ & $186(38.5)$ & II (34.4) \\
\hline Unemployed, adult & $93(18.1)$ & $83(17.2)$ & $10(3 \mid .3)$ \\
\hline
\end{tabular}

Note: Percentage may not add to $100 \%$ due to rounding.

Abbreviation: ADHD, attention-deficit/hyperactivity disorder. 
specialist. The mean age at referral was 33 years; $60.2 \%$ of referrals were males. There was no difference in mean age between males and females.

\section{Analyses}

Reasons for referral to adult ADHD specialist

Triggers for patient referral were referring physician mentions ADHD or symptoms implying ADHD, with no comorbid symptoms noted $(59.2 \% ; 305 / 515)$; referring physician mentions ADHD with other comorbid symptoms (15.3\%; 79/515); patient/family suspects ADHD (7.6\%; 39/515) with no comorbid symptoms noted; patient/family suspects ADHD and patient has comorbid symptoms $(2.5 \% ; 13 / 515)$; or patient mentions symptoms not limited to ADHD (15.3\%; 79/515). Most (91.7\% [472/515]) referrals were made by family physicians, $5.8 \%(30 / 515)$ were made by nonspecialist psychiatrists, and $2.5 \%$ (13/515) were referred by "other" physicians, e.g., a psychologist.

\section{Delay from referral request to actual patient consultation by ADHD specialist}

One-third of patients had a delay of $\geq 3$ months between referral and initial consultation with an adult ADHD specialist; $31 \%$ were seen by a specialist within a month (Figure 1).

\section{Prevalence of ADHD symptoms}

Inattention was the predominant symptom for patients with confirmed ADHD and was experienced by $\sim 80 \%$ of patients (Figure 2). Other commonly reported ADHD symptoms were procrastination, disorganization, impulsivity, hyperactivity, emotional dysregulation, and memory impairment.

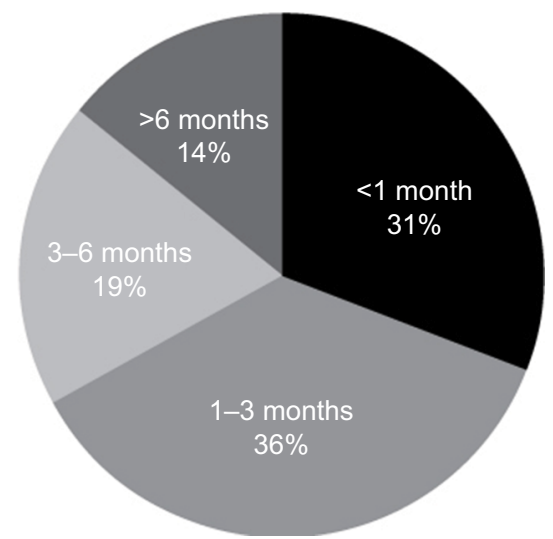

Figure I Delay between referral and the initial consultation with the adult ADHD specialist $\left(n=505^{a}\right)$.

Note: a $A$ total of 10 of the 515 patients' CRFs did not have the referral date and are not included in this figure.

Abbreviations: ADHD, attention-deficit/hyperactivity disorder; CRF, case report form.

\section{Prevalence of comorbid symptoms}

No psychiatric comorbid symptoms were noted by the referring physician in $66.8 \%$ (344/515) of case referrals. In total, $69.4 \%(335 / 483)$ of patients with confirmed ADHD had $\geq 1$ comorbid symptom (reported by either the specialist or the referring physician). Anxiety and depression were the most common psychiatric comorbid symptoms (Figure 3).

\section{Impact of ADHD on patients' daily life}

Almost all (99.6\% [481/483]) patients with confirmed ADHD reported an impact on their daily life. School or work were particularly affected (Figure 4).

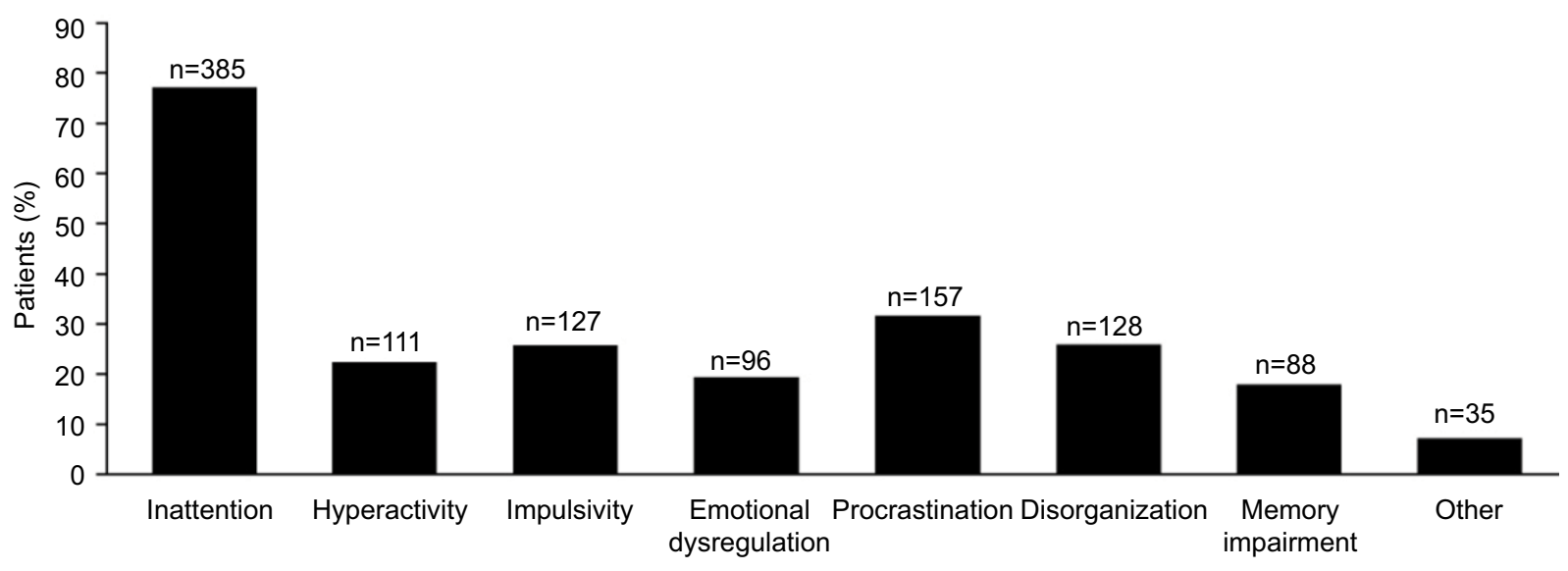

Figure 2 Prevalence of ADHD symptoms ${ }^{a}$ among patients with confirmed ADHD $(n=483)$.

Notes: ${ }^{a}$ Combined from reason for referral, complaints as verbalized by the patient, and symptoms as interpreted by the specialist. Patients could have more than one symptom.

Abbreviation: ADHD, attention-deficit/hyperactivity disorder. 


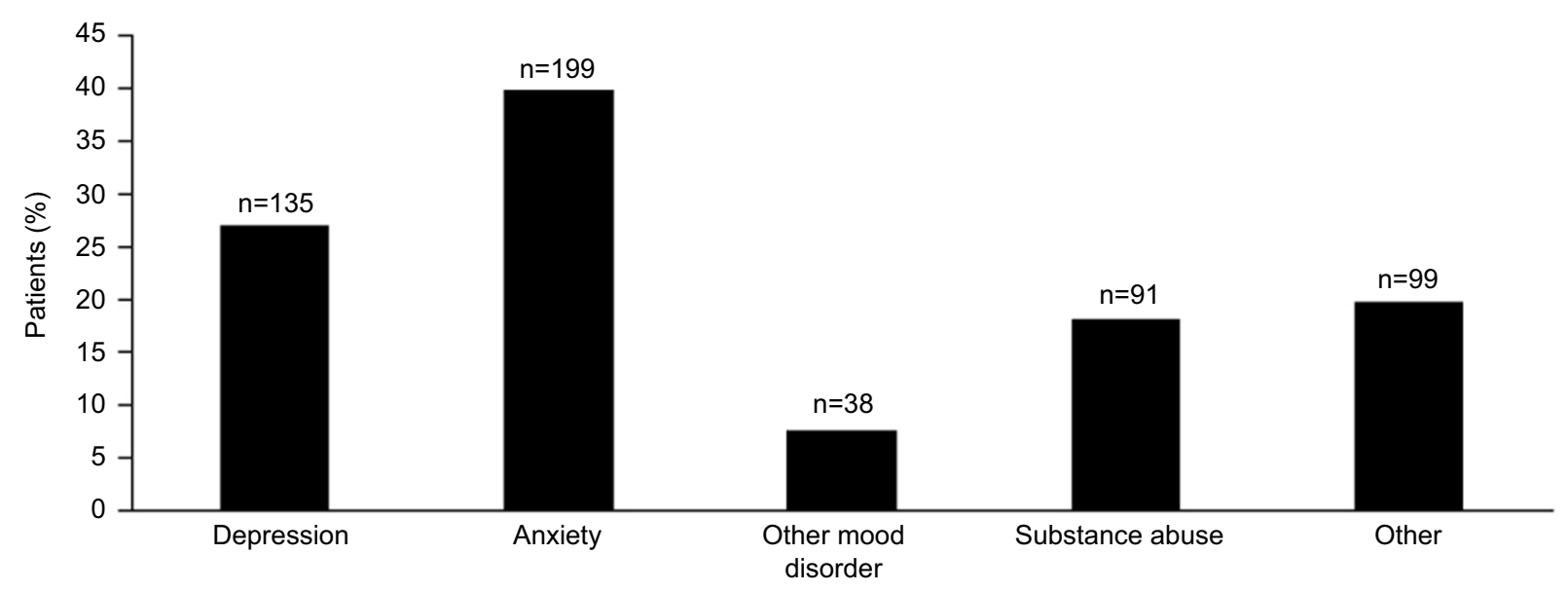

Figure 3 Prevalence of comorbid symptoms $s^{a}$ noted by the specialist or the referring physician among patients with confirmed ADHD ( $n=483$ ).

Notes: "Comorbidities were interpreted only as "comorbid symptoms" as they were not always reported in the CRFs as a specific, confirmed DSM-5 diagnosis. Patients could have more than one comorbid symptom.

Abbreviations: ADHD, attention-deficit/hyperactivity disorder; CRF, case report form; DSM-5, Diagnostic and Statistical Manual of Mental Disorders, Fifth Edition.

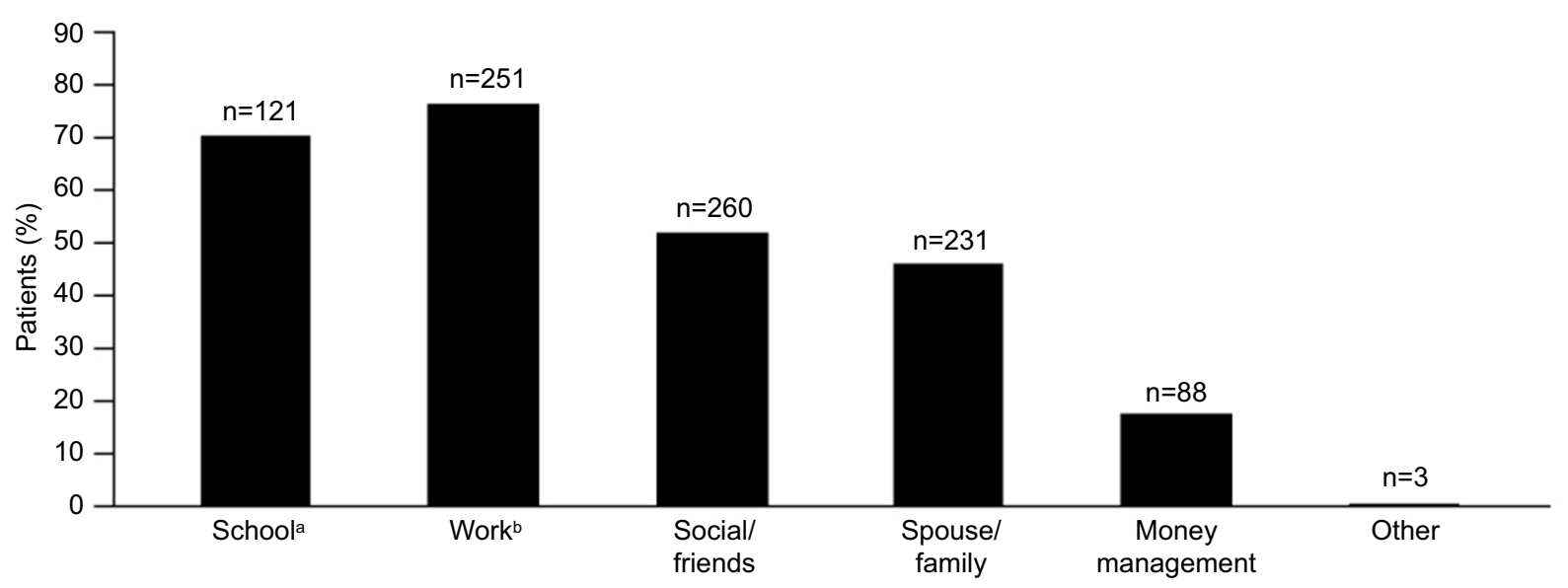

Figure 4 Impact of ADHD on daily life of adults with confirmed ADHD ( $n=483)$.

Notes: Patients could report impact on more than one area of daily life. alncludes all college/university students with confirmed ADHD ( $\mathrm{n}=166)$. ${ }^{\mathrm{b}}$ Includes all patients except college/university students with confirmed ADHD ( $n=3 \mid 7)$.

Abbreviation: ADHD, attention-deficit/hyperactivity disorder.

\section{Employment status}

All but 17.2\% (83/483) of patients with confirmed ADHD were either employed $(48.4 \% ; 234 / 483)$ or a college or university student $(34.4 \% ; 166 / 483)$.

\section{Follow-up care after ADHD diagnosis}

In patients diagnosed with $\mathrm{ADHD}$, pharmacological $\mathrm{ADHD}$ treatments were recommended as follows: stimulant monotherapy, $79.3 \%$ (383/483); non-stimulant monotherapy, $8.5 \%$ (41/483); and stimulant plus non-stimulant, 8.1\% (39/483); a stimulant/non-stimulant medication was not recommended for $4.1 \%(20 / 483)$ of patients. Patients were returned to the care of the referring physician in $21.1 \%(102 / 483)$ of cases. A further $20.5 \%$ (99/483) of patients were stabilized on treatment and then returned to the care of their referring physician.
Follow-up was retained by the specialist in $58.4 \%$ (282/483) of patients with ADHD. Although no statistical testing was performed, patient characteristics (sex, age, or comorbid symptoms) did not appear to influence which patients were retained by the specialist and which patients were sent back to the referring physician; conversely, there was considerable variability between adult ADHD specialists in the percentage of patients who were retained. For example, one physician retained no patients, another retained $10 \%$, and three physicians retained $100 \%$ of patients.

\section{Discussion}

The results from this survey of referral patterns provide valuable insights into diagnosis and treatment of uncomplicated ADHD in adults in real-world practice in Canada. Following 
referral of patients with suspected symptoms of ADHD by family physicians, the diagnosis of ADHD was confirmed by a specialist in most cases, thereby indicating that the family physicians were able to correctly identify ADHD patients in their practice. This agreement between primary and specialist care was achieved despite infrequent use of standardized instruments for ADHD diagnosis in daily practice. In the majority of cases (66.8\%), no psychiatric comorbid symptoms were noted by the referring physician at the time of referral. Therefore, although cases appeared unlikely to be complex from the case notes, the patients were still referred to specialists. However, as many patients $(69.4 \%)$ had at least one comorbid symptom noted (reported by either the specialist or the referring physician), it cannot be excluded that a comorbid symptom (although not always noted by the referring physician) contributed to the decision to refer.

The demographic data collected in this survey are consistent with published epidemiological data, which suggest that adult ADHD is more likely to be diagnosed in males than females. ${ }^{5} \mathrm{ADHD}$ is often associated with high levels of unemployment compared with the general population ${ }^{12-14}$ and with "on-the-job difficulties" in students. ${ }^{15}$ Indeed, data from an international web-based survey of adults in Europe and the US showed that, compared to individuals without ADHD, those with ADHD were less likely to be employed (55.3\% versus $64.2 \%$, respectively, in Europe and $62.0 \%$ versus $78.0 \%$, respectively, in the US). ${ }^{16}$

In this survey, $17 \%$ of the ADHD population was unemployed, compared with an unemployment rate of $7 \%$ overall in Canada. ${ }^{17}$ The high rates of unemployment could also be attributed to psychiatric comorbid symptoms, as the unemployment rate for individuals with mood and anxiety disorders is higher than that in the general population. ${ }^{18}$ The survey highlighted delays from referral request to consultation with an ADHD specialist; for adults without comorbid symptoms (approximately one-third of adults in this study), these delays could be avoided if family physicians were trained and more confident in dealing with uncomplicated cases of adult ADHD. Referrals to specialist clinics in Canada for adult ADHD were predominantly for patients with common ADHD symptoms such as inattention (reported in $80 \%$ of cases). This finding is consistent with a published survey of 3574 patients with adult ADHD in which inattention was the most common and disabling symptom. ${ }^{19}$ Where psychiatric comorbid symptoms were noted, the most common were anxiety and depression, which is consistent with reports in the literature. ${ }^{5}$

Data from this survey showed that ADHD had a multifaceted impact on patients' daily lives, affecting work and school, as well as relationships and finances. This pattern of negative impact on aspects of workplace/social functioning is consistent with data reported in the literature. ${ }^{2}$ Indeed, significant impairment of day-to-day functioning, cognition, and social interactions are reported in the literature for adults with ADHD, irrespective of comorbidities. ${ }^{5}$ Specialist consultation was delayed by $\geq 3$ months in one-third of referrals. If these cases could have been managed within primary care, this delay in receiving a diagnosis and treatment would not have occurred. Approximately $40 \%$ of patients were returned to the referring physician either immediately or after stabilization on treatment, suggesting that a considerable number of cases could potentially have been managed within primary care. No specific trends were shown for which patients were retained by the ADHD specialist versus which patients were returned to the referring physician.

In patients diagnosed with $\mathrm{ADHD}$, pharmacologic $\mathrm{ADHD}$ treatments were recommended in $>95 \%$ of cases, with stimulant monotherapy the most frequently prescribed (79.3\%). Family physicians in Canada may not only be reluctant to diagnose adult ADHD but also may lack confidence in prescribing treatments for ADHD. ${ }^{20}$ This may be due to a lack of experience in managing ADHD throughout the patient's lifespan and the confusion created by comorbid symptoms. It remains to be seen if reluctance by physicians to prescribe pharmacologic treatments for ADHD may also be affected by the inclusion of psychostimulants in the safe prescribing standard of care document published by the College of Physicians and Surgeons of British Columbia (CPSBC) in June 2016. ${ }^{21}$

Canadian guidelines state that "in Canada, adequate levels of service delivery for ADHD are only going to be feasible when it becomes a disorder that primary care providers are trained to deal with, and when they can access specialist care when needed". The Canadian guidelines recommend that family physicians diagnose and treat uncomplicated ADHD in adults and acknowledge that where cases are more complicated, referral to a specialist is advisable. However, following diagnosis and treatment by the specialist, continuing care may be provided by family physicians, even in more complicated cases. ${ }^{9}$ In order to cope with the challenge of managing adult ADHD and the burden that it places on the health care system, primary care physicians may need additional education and support. ${ }^{9}$

\section{Limitations}

The interpretation of the results reported here should be viewed with caution because of the descriptive and retrospective nature of the data. Information on psychiatric 
comorbid symptoms at the time of referral was reliant on information provided by the family physician at referral; therefore, assessment of comorbid symptoms was performed in a nonstandardized manner in this study. In addition, there was insufficient information (both from the family physician and the specialist) to report comorbidities as diagnosed conditions, and so we have used the term comorbid symptoms. Additional limitations include the lack of data for lifetime versus current comorbid symptoms. Adults were only included in the survey if they had no obvious family history of ADHD; however, it should be noted that information about family history of ADHD by its nature may be unreliable. The study was designed to provide information on the typical patients and patient flow that are seen in the process of referral to adult ADHD specialists in Canada. However, the authors acknowledge that inclusion of a larger number of cases would enhance the information gained from the survey.

\section{Conclusion}

The results from this survey of adult referrals in Canada showed that ADHD diagnosis was specialist confirmed in most cases, showing that the referring practitioner was correct in his or her suspected diagnosis of ADHD. Although appropriate referral is important and family physicians should feel comfortable with referring their patients to specialists when necessary, referrals were made even when patients presented with predominantly common ADHD symptoms and no apparent psychiatric comorbid symptoms. This could indicate that family physicians are less confident in diagnosing adult ADHD. However, although in most referrals (67\%), no psychiatric comorbid symptoms were noted, $69 \%$ of patients had $\geq 1$ such symptom (reported by the specialist or referring physician), so it may be that comorbid symptoms, although not always noted at referral, contributed to the decision to refer.

Measures such as relevant training including better knowledge of current pharmacologic treatments and correct use of available guidelines are needed to reinforce family physicians' confidence in diagnosing uncomplicated cases of suspected adult ADHD. This could also be extended to educational initiatives to increase family physicians' confidence in diagnosing comorbid ADHD. The fact that around two-thirds of adults with ADHD have comorbid symptoms brings into question the practicality of the Canadian guidelines in advising that only uncomplicated ADHD is treated by family physicians.

Family physicians may feel able to manage the follow-up of a case once diagnosis has been confirmed by the specialist. This should boost confidence in their ability to diagnose
ADHD with comorbid symptoms, eventually resulting in fewer referrals to specialty clinics. This trend could be examined in a future study, with the hope that results may show a reversal of the current disconnect between primary and specialist care. Improvements in training and education of family physicians may result in faster access to treatment, ultimately reducing the impact of untreated ADHD on various aspects of patients' daily lives.

\section{Acknowledgments}

The authors wish to thank the ADHD specialists who contributed case information for this survey. Under the direction of the authors, Joanna Wright, DPhil, Caudex, Oxford, UK, and Denise Graham, $\mathrm{PhD}$, Caudex, Oxford, UK, provided writing assistance for this publication, funded by Shire International $\mathrm{GmbH}$. Editorial assistance in formatting, proofreading, copyediting, fact checking, and coordination and collation of comments was also provided by Caudex, funded by Shire International $\mathrm{GmbH}$. The authors wish to thank Carol Heggie (formerly of Shire) for her contribution to the study. Tamara Werner-Kiechle of Shire International $\mathrm{GmbH}$ also reviewed and edited the manuscript for scientific accuracy. Although employees of Shire were involved in the design, collection, analysis, interpretation, and fact checking of information, the content of this manuscript, the interpretation of the data, and the decision to submit the manuscript for publication in International Journal of General Medicine were made by the authors independently. This research was funded by Shire Development, LLC. Shire International GmbH provided funding to Caudex, Oxford, UK, for support in writing and editing this manuscript. Data from this manuscript were presented at the 12th Annual CADDRA ADHD Conference, Ottawa, Canada, 2016.

\section{Author contributions}

James G Burns and Samuel Schaffer contributed to the conception and design of the study. All authors contributed to the analysis and interpretation of the data and revised the article critically for content. All authors reviewed and approved the final draft of the manuscript and have agreed to act as guarantors of the work.

\section{Disclosure}

Larry J Klassen has received research support from Shire and has been on advisory boards and speaker bureaus for Shire, Ironshore, Janssen, Lundbeck, Pfizer, Purdue, and Sunovion. $\mathrm{C}$ Matthew Blackwood has been on advisory boards and speaker bureaus for Shire and is on the Board of Directors for CADDRA. Christopher J Reaume and James G Burns 
are employees of Shire. Samuel Schaffer was an employee of Shire at the time of the study. The authors report no other conflicts of interest in this work.

\section{References}

1. Bonvicini C, Faraone SV, Scassellati C. Attention-deficit hyperactivity disorder in adults: a systematic review and meta-analysis of genetic, pharmacogenetic and biochemical studies. Mol Psychiatry. 2016;21(7):872-884.

2. Chandra S, Biederman J, Faraone SV. Assessing the validity of the age at onset criterion for diagnosing ADHD in DSM-5. JAtten Disord. In press 2016.

3. Biederman J, Faraone SV, Spencer TJ, Mick E, Monuteaux MC, Aleardi M. Functional impairments in adults with self-reports of diagnosed ADHD: a controlled study of 1001 adults in the community. J Clin Psychiatry. 2006;67(4):524-540.

4. Buoli M, Serati M, Cahn W. Alternative pharmacological strategies for adult ADHD treatment: a systematic review. Expert Rev Neurother. 2016;16(2):131-144.

5. Fayyad J, Sampson NA, Hwang I, et al; WHO World Mental Health Survey Collaborators. The descriptive epidemiology of DSM-IV Adult ADHD in the World Health Organization World Mental Health Surveys. Atten Defic Hyperact Disord. 2017;9(1):47-65.

6. Pineiro-Dieguez B, Balanza-Martinez V, Garcia-Garcia P, Soler-Lopez B; CAT Study Group. Psychiatric comorbidity at the time of diagnosis in adults with ADHD: the CAT study. J Atten Disord. 2016;20(12):1066-1075.

7. Chamberlain SR, Ioannidis K, Leppink EW, Niaz F, Redden SA, Grant JE. ADHD symptoms in non-treatment seeking young adults: relationship with other forms of impulsivity. CNS Spectr. 2017;22(1):22-30.

8. Asherson P, Buitelaar J, Faraone SV, Rohde LA. Adult attentiondeficit hyperactivity disorder: key conceptual issues. Lancet Psychiatry. 2016;3(6):568-578.

9. CADDRA. Canadian ADHD Practice Guidelines. 3rd ed. 2011. Available from: http://caddra.ca/pdfs/caddraGuidelines2011.pdf. Accessed February 14, 2017.

10. Searight HR, Burke JM, Rottnek F. Adult ADHD: evaluation and treatment in family medicine. Am Fam Physician. 2000;62(9):2077-2086.
11. American Psychiatric Association. Diagnostic and Statistical Manual of Mental Disorders, Fifth Edition (DSM-5). Arlington, VA: American Psychiatric Publishing; 2013.

12. Kupper T, Haavik J, Drexler H, et al. The negative impact of attentiondeficit/hyperactivity disorder on occupational health in adults and adolescents. Int Arch Occup Environ Health. 2012;85(8):837-847.

13. Erskine HE, Norman RE, Ferrari AJ, et al. Long-term outcomes of attention-deficit/hyperactivity disorder and conduct disorder: a systematic review and meta-analysis. J Am Acad Child Adolesc Psychiatry. 2016;55(10):841-850.

14. Young JL, Goodman DW. Adult attention-deficit/hyperactivity disorder diagnosis, management, and treatment in the DSM-5 Era. Prim Care Companion CNS Disord. 2016;18(6).

15. Shifrin JG, Proctor BE, Prevatt FF. Work performance differences between college students with and without ADHD. J Atten Disord. 2010;13(5):489-496.

16. Able SL, Haynes V, Hong J. Diagnosis, treatment, and burden of illness among adults with attention-deficit/hyperactivity disorder in Europe. Pragmat Obs Res. 2014;5:21-33.

17. Trading Economics [webpage on the Internet]. Canada Unemployment Rate. 2017. Available from: http://www.tradingeconomics.com/canada/ unemployment-rate. Accessed June 9, 2017.

18. Government of Canada [webpage on the Internet]. Mood and Anxiety Disorders in Canada. Fast Facts from the 2014 Survey on Living with Chronic Diseases in Canada. 2015. Available from: https://www. canada.ca/en/public-health/services/publications/diseases-conditions/ mood-anxiety-disorders-canada.html. Accessed February 14, 2017.

19. Vitola ES, Bau CH, Salum GA, et al. Exploring DSM-5 ADHD criteria beyond young adulthood: phenomenology, psychometric properties and prevalence in a large three-decade birth cohort. Psychol Med. 2017;47(4):744-754.

20. Faraone SV, Spencer TJ, Montano CB, Biederman J. Attention-deficit/ hyperactivity disorder in adults: a survey of current practice in psychiatry and primary care. Arch Intern Med. 2004;164(11):1221-1226.

21. Resident Doctors of BC. College Board Adopts New Professional Standard on Safe Prescribing. 2016. Available from: https://residentdoctorsbc.ca/college-board-adopts-new-professional-standard-on-safeprescribing/. Accessed February 21, 2017. 


\section{Supplementary materials}

\section{Table SI CRF}

Case Number:

Requirements for eligibility: Does this request ask for consultation in regards to ADHD or attentional issues? No expressed or known prior family history of ADHD at referral: No expressed or known prior childhood history of ADHD at referral:

Details of Referral to ADHD Specialist

1. Date of consultation request: (must be in last 2 years, i.e. after January 2012)

2. Referring MD: $\square$ GP/FM $\square$ Other

3. Reason/trigger for consultation request as per referral note:

\section{ADHD Specialist INITIAL Patient Assessment}

4. Date of first patient consultation: ...............................

5. Patient age: 6. Patient gender: $\square$ Male $\square$ Female

7. Complaints as verbalized by patient to ADHD specialist at initial assessment:

\section{ADHD symptoms as interpreted by ADHD specialist:}

9. How had these impacted issues of daily life?

$\square$ Work $\square$ Spouse/Family $\square$ Social/Friends $\square$ Money Management $\square$ Other (specify)...

10. Employment status: $\square$ Currently employed $\square$ Student $\square$ Homemaker $\square$ Not working $\square$ Unable to work

11. ADHD diagnosis confirmed by ADHD specialist: $\square$ Yes $\square$ No

12. Comorbid psychiatric conditions noted by ADHD specialist:

a. History: $\square$ None $\square$ Anxiety $\square$ Depression $\square$ Substance abuse $\square$ Other: (specify).

b. Current: $\square$ None $\square$ Anxiety $\square$ Depression $\square$ Substance abuse $\square$ Other: (specify).

13. Was the patient ADHD treatment naĩve at referral?

$\square$ Yes $\square$ No, previous treatment tried: $\square$ Stimulant $\square$ Non-stimulant

14. ADHD Treatment recommended by ADHD specialist: $\square$ Stimulant $\square$ Non-stimulant

15. Plan for patient's ongoing ADHD follow up care:

$\square$ Recommend treatment and return to GP $\square$ Stabilize on treatment and return to GP $\square$ Keep patient for ADHD care Abbreviations: ADHD, attention-deficit/hyperactivity disorder; CRF, case report form; FM, family medicine; GP, general practitioner; MD, Doctor of Medicine. 
Table S2 Categories and predefined list of words used to list the symptoms for each patient

\begin{tabular}{ll}
\hline Category & Predefined list of words \\
\hline Inattention & $\begin{array}{l}\text { Inattention, problems with concentration, distraction, carelessness, zones out, problems focusing, daydreams, } \\
\text { making mistakes at work, scatterbrained } \\
\text { Hyperactivity }\end{array}$ \\
$\begin{array}{l}\text { Impulsivity } \\
\text { Emotional dysregulation }\end{array}$ & $\begin{array}{l}\text { Emotional dysregulation, frustration, irritability, conflict, oppositional, agitated, anger problems, explosive, mood } \\
\text { liability }\end{array}$ \\
Procrastination & $\begin{array}{l}\text { Procrastinates, lack of motivation, does not finish work, inability to complete tasks, decreased interest, hands in } \\
\text { assignments late }\end{array}$ \\
Disorganization & Disorganized, poor time management \\
Poor memory & Poor memory, forgetfulness \\
Others & General cognitive problems, unable to read, difficulty reading, problems with understanding, processing speed slow, \\
& difficulty retaining information \\
\hline
\end{tabular}

\section{Publish your work in this journal}

The International Journal of General Medicine is an international, peer-reviewed open-access journal that focuses on general and internal medicine, pathogenesis, epidemiology, diagnosis, monitoring and treatment protocols. The journal is characterized by the rapid reporting of reviews, original research and clinical studies across all disease areas.
The manuscript management system is completely online and includes a very quick and fair peer-review system, which is all easy to use. Visit http://www.dovepress.com/testimonials.php to read real quotes from published authors. 